\title{
ANALYSIS OF MICROSTRIP TRIANGULAR FRACTAL ANTENNAS FOR WIRELESS APPLICATION
}

\author{
Dr. G. Karunakar ${ }^{1}$, V. Dinesh ${ }^{2}$ \\ Associate Professor, Department of ECE, GIT, GITAM University, Visakhapatnam, India ${ }^{1}$ \\ M.Tech (RF\&ME), Department of ECE, GIT, GITAM University, Visakhapatnam, India ${ }^{2}$
}

\begin{abstract}
The microstrip antennas take any shape like square, rectangular, triangle and so on. They provide normally single resonance frequency with high quality factor because of narrow bandwidth. However, the fractal antennas are able to provide either multi-band resonances or broad bandwidth because of the self-similar and space-filling properties.

In present paper, a study is made on Sierpinski gasket triangular fractal antenna for single and multiband applications. Design and simulation is done using HFSS 13.0 software and fabrication is done using photolithography etching method which gives adequate result for this type of antennas. By using vector network analyzer E5071C the designed antennas are tested and various plots like return loss, VSWR, smith chart and polar plot are verified. The designed antennas are used in implantable medical (IMD) applications and other wireless applications.
\end{abstract}

Keywords: HFSS, IMD, Triangular Fractal antenna

\section{INTRODUCTION}

The Triangular Fractal Antenna was the first effectively disconnected. This phenomenon is equivalent example of multiband fractal shaped antenna. This to the active region found in the log-periodic array. multiband behavior stems from the self-similarity property that all fractal shapes share. The whole shape is constructed by clusters which are scaled down versions of the whole structure. The antenna design will be obtained through a perturbation of the classic Triangular fractal based on a reduction of the fractal iteration and a modification of the scale properties.

The Triangular Fractal Antenna is a good example of a self similar antenna that shows multiband behavior. This fractal-shaped antennas may be constructed as plate or wire realizations in both monopole and dipole version too.

The Triangular Fractal Antenna is the first candidate for a fractal antenna due to its resemblance to the triangular or bow-tie antenna. The Triangular Fractal Antenna monopole shows several resonance bands. Actually, the Triangular Fractal Antenna monopole have a $\log$-periodic behavior with bands spaced by a factor $s=2$ and with a moderate bandwidth of $21 \%$. The antenna is matched approximately at frequency.

$$
f_{n} \approx 0.26 \frac{c}{h} S^{n}
$$

Where $\mathrm{s}=2$ is the $\log$-period constant, $\mathrm{n}$ is a natural number, $c$ is the speed of light in vacuum and $h$ is the height of the largest TFA. The Triangular Fractal Antenna monopole shows a similarity among the patterns because the surface current concentrates at each band over a properly scaled substructure on the antenna, which has the main contribution to the overall radiation pattern. This region is smaller when frequency is increased. The current does not reach the top of the antenna at highest frequency and a large area of the structure becomes this way
The Triangular Fractal Antenna is a self-similar structure. In such an ideal Triangle, each one of its three main parts is exactly equal to the whole object, but scaled by a factor of two and so each of the three gaskets that compose any of those parts. The self-similarity properties of the fractal shape are translated into its electromagnetic behavior and results in a multiband antenna. The variation on the antenna's flare angle shifts the operating bands, changes the impedance level, and alters the radiation patterns.

The current distribution on the Triangular Fractal Antenna shows that the most of the current density concentrates on the joints and edges of the different triangle clusters that make up the Triangular Fractal Antenna.

The first few stages in the construction of the Triangular Fractal Antenna are shown in Figure 1. The procedure for geometrically constructing this fractal begins with an equilateral triangle contained in the plane, as illustrated in Stage 0. The next step in the construction process (see Stage 1 of Figure1) is to remove the central triangle with vertices that are located at the midpoints of the sides of the original triangle, shown in Stage 0. This process is then repeated for the three remaining triangles, as illustrated in Stage 2. The next two stages (i.e., Stages 3 and 4) in the construction of the Triangular Fractal Antenna are also shown in Figure 1.

The Triangular Fractal is generated by carrying out this iterative process an infinite number of times. 


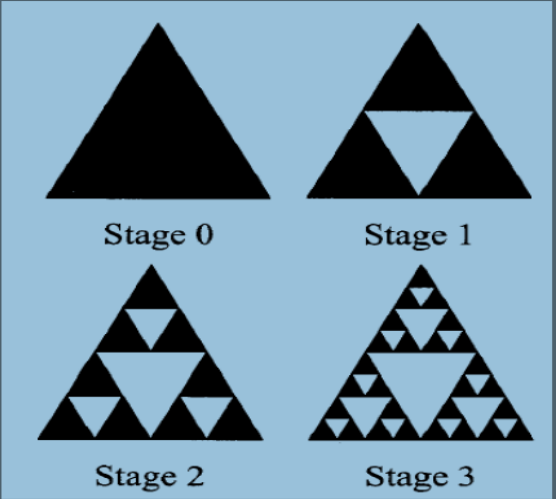

Figure 1: Several stages in the construction of a Triangular Fractal Antenna.

It is easy to see from this definition that the Triangular Fractal Antenna is an example of a self-similar fractal. From an antenna engineering point of view, a useful interpretation of Figure 1 is that the black triangular areas represent a metallic conductor, whereas the white triangular areas represent regions where metal has been removed. The Triangular Fractal Antenna been shown to be an excellent candidate for multiband applications. . The antenna design will be obtained through a perturbation of the classic Triangular fractal based on a reduction of the fractal iteration and a modification of the scale properties.

\section{DESIGN APPROACH FOR PROPOSED FRACTAL ANTENNA}

The construction of the proposed fractal shape is carried out by applying a finite number of times an iterative process performed on a simple starting topology. According to the properties of self similarity, the fractal dimension Ds of a set $\mathrm{A}$ is defined as:

$\mathrm{D}_{\mathrm{s}}=\log (\mathrm{N}) / \log (\mathrm{r})$

Where $\mathrm{N}$ is the total number of distinct copies similar to $\mathrm{A}$ and $\mathrm{A}$ is scaled down by a ratio of $1 / \mathrm{r}$.

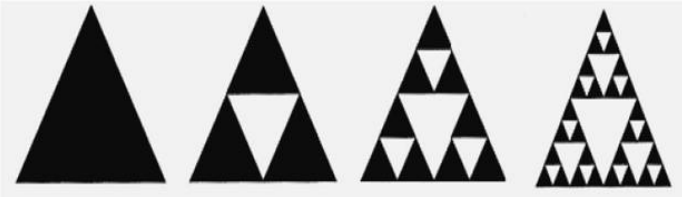

Figure 2: Basic concept of Iterations.

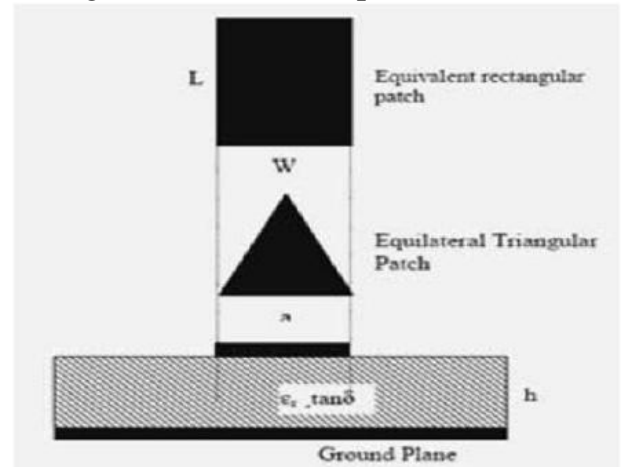

Figure 3: Equilateral triangular patch \& equivalent rectangular patch
Fig 3 shows an equilateral triangular patch and its equivalent rectangular patch antenna. The resonance frequency of the equilateral triangular patch can be determined by;

$$
f_{r}=\frac{2 c}{3 L_{e f f} \sqrt{\varepsilon_{r, d y n}^{*}}}
$$

Where, $\mathrm{c}$ is the velocity electromagnetic wave in free space. The $L_{\text {eff }}$ is the effective length of the equivalent rectangular patch $[\mathrm{L}=\mathrm{a}, \mathrm{W}=(\sqrt{ } 3 / 2) \mathrm{a}]$ and $\varepsilon_{r, d y n}^{*}$ is the dynamic relative permittivity of the triangular shown Fig 3. The dynamic relative permittivity of the equivalent patch antenna is given by;

$$
\varepsilon_{r, d y n}^{*}=\frac{C_{d y n}^{*}\left(\varepsilon_{r}^{*}, h, W\right)}{C_{d y n}^{*}\left(\varepsilon_{r}^{*}=1, h, W\right)}
$$

Where is the complex dynamic capacitance of equivalent rectangular patch and

$\varepsilon_{r_{e f f}}^{*}\left(\varepsilon_{r}^{*}, h, W\right)=\frac{\varepsilon_{r}+1}{2}+\left\{\frac{\varepsilon_{r}+1}{2}\left(1+\frac{12 h}{a}\right)^{-\frac{1}{2}}\right\}$

Where all the parameters have usual meaning.

\section{DESIGN METHOD}

The Flared fractal antenna has been designed on the FR4 substrate with dielectric constant 4 and thickness $1.6 \mathrm{~mm}$.

The Triangular Fractal Antenna is designed using the equation

$f_{r}=0.3 \cos (\alpha) \sqrt{\frac{2.5}{\varepsilon_{r}}} \frac{c}{h} S^{n}$

Where

$\mathrm{f}_{\mathrm{r}}=$ resonant frequency,

$\boldsymbol{\alpha}=$ flare angle (the angle subtended at the apex of the triangle),

$€_{\mathrm{r}}=$ relative permittivity of the substrate,

$\mathrm{h}=$ height of the gasket,

$\mathrm{s}=$ scale factor $(\log$ periodic $)$

$\mathrm{n}=$ iteration/stage.

Equation 2 is different from the design equation mentioned in by a factor of 2 in the argument $\boldsymbol{\alpha}$. This discrepancy was attributed to the feeding of the antenna by a micros trip line, in contrast to a direct feed from the ground plane as in. Hence the micro strip feed also helps in reducing the size of the gasket.

The heights $\boldsymbol{h}_{\boldsymbol{n}}$ at different stages $\boldsymbol{n}$ of the triangular fractal antenna, for a constant scaling factor $s$, can be calculated as:

$$
h_{1}=0.3 \cos (\alpha) \sqrt{\frac{2.5}{\varepsilon_{r}}} \frac{c}{f_{r_{1}}} s
$$

$h_{n}=\frac{h_{n-1}}{s}$ for $n \geq 2$

.The Remaining parameters of the triangular fractal antenna can be found by simple trigonometry, 


$$
\begin{gathered}
l x=2 h \tan \left(\frac{180-\alpha}{2}\right) \\
l_{1}=l_{2}=\sqrt{h^{2}+(a / 2)^{2}}
\end{gathered}
$$

Where

$l_{x}=$ length of the edge opposite the flare angle $\alpha$, $l_{1}=l_{2}=$ length of the other two edges.

Hence, the whole structure can be drawn with the knowledge of the flare angle $\boldsymbol{\alpha}$ and the height $\boldsymbol{h}$ is shown in fig 3.

In order to calculate the side of the triangular fractal antenna the following parameters are required:

$\mathrm{C}=3 \times 10^{8} \mathrm{~m} / \mathrm{sec}$

$\varepsilon_{r, d y n}^{*}=4.4(\mathrm{FR} 4$ substrate $)$

$L_{\text {eff }}=\sqrt{3} \cdot a / 2$

$f_{\mathrm{r}}=2.4 \mathrm{GHz}$

Using the above formulas for resonant frequency, the side of the triangle calculated $\mathrm{a}=32 \mathrm{~mm}$.

\section{SIMULATION RESULTS}

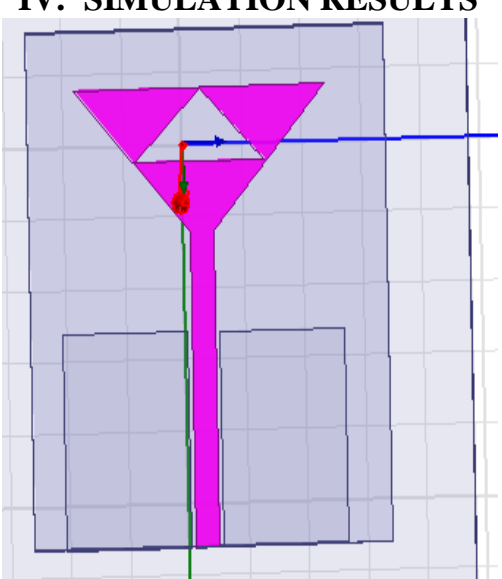

Figure 4: HFSS design for triangular fractal antenna $1^{\text {st }}$ iteration

The first iteration produces a return loss of $-11.25 \mathrm{~dB}$ at $2.37 \mathrm{GHz}$ and a return loss of $-10.6 \mathrm{~dB}$ at $9 \mathrm{GHz}$. VSWR of 1.26 at $2.4 \mathrm{GHz}$ and 1.3 at $9.6 \mathrm{GHz}$

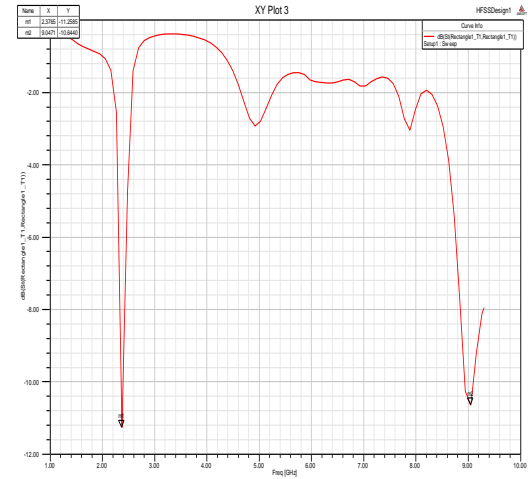

Figure 5 : Return loss curve of the triangular fractal antenna $1^{\text {st }}$ iteration

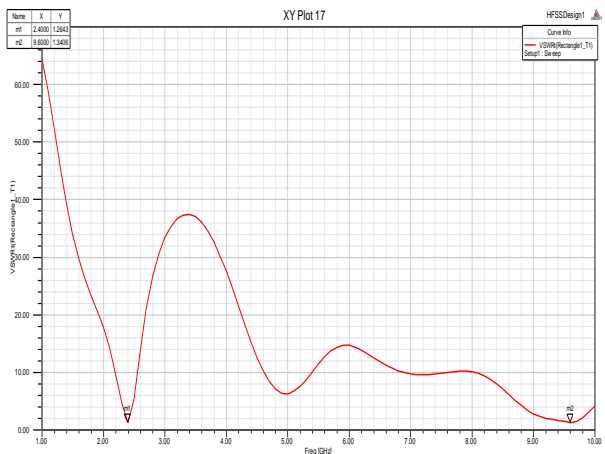

Figure 6: VSWR curve of the triangular fractal antenna $1^{\text {st }}$ iteration

Applying the second iteration for the original flared monopole brings an improvement in the return loss and an improvement in the bandwidth of the antenna. The structure of the antenna after the second iteration is described as given below.

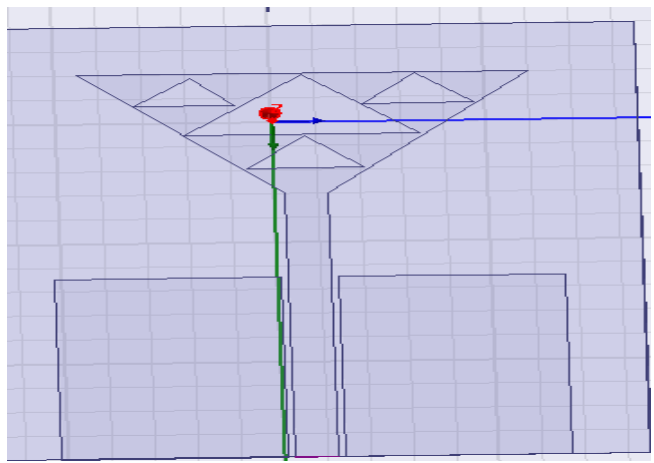

Figure 7: HFSS design for triangular fractal antenna $\left(2^{\text {nd }}\right.$ iteration)

The return losses observed from the structure shows a return loss of $-21.2 \mathrm{~dB}$ at $2.4 \mathrm{GHz}$ and a return loss of $-22 \mathrm{~dB}$ at $9.6 \mathrm{GHz}$. And the return loss is been improved to $-21 \mathrm{~dB}$ at $2.4 \mathrm{GHz}$ and from $-16 \mathrm{~dB}$ to $-22 \mathrm{~dB}$ at $9.6 \mathrm{GHz}$, VSWR 1.2 at $2.4 \mathrm{GHz}$ and 1.3 at $9.6 \mathrm{GHz}$.

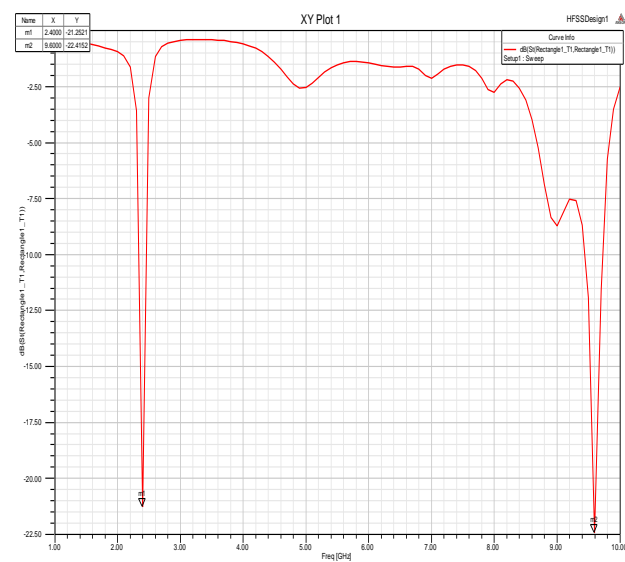

Figure 8 : Return loss curve of the triangular fractal antenna $2^{\text {nd }}$ iteration 


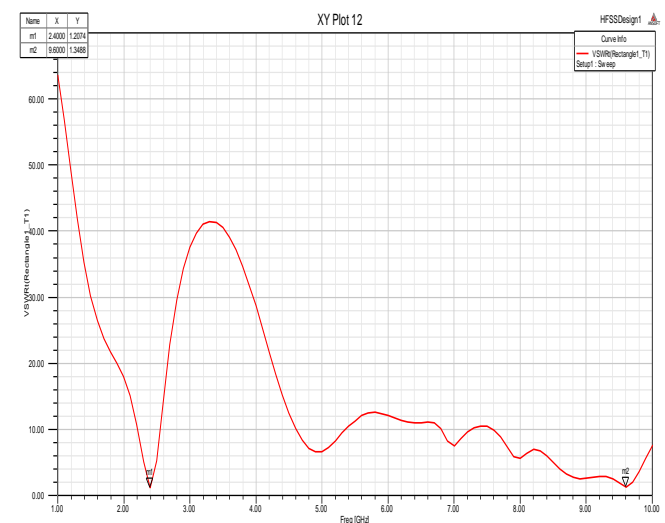

Figure 9: VSWR curve of the triangular fractal antenna $2^{\text {nd }}$ iteration

\section{CONCLUSIONS}

In this work, various fractal antennas have been designed and tested. The results obtained are in agreement with the desired results. Triangular fractal antenna is designed for first and second iterations first iteration of this antenna is resonated at $1.6 \mathrm{GHz}$ and second iteration of this antenna is resonated at $4.4 \mathrm{GHz}$ and $6.5 \mathrm{GHz}$

The Triple Band Diamond Fractal Antenna discussed above is suitable for Wi-Max applications. Antenna resonates at three frequencies, i.e. $2.8 \mathrm{GHz}, 7.1 \mathrm{GHz}$ and $9.5 \mathrm{GHz}$ and percentage bandwidths are $11.2 \%, 3.35$ and $3.02 \%$ respectively. Very broad radiation patterns have been obtained which seems to be adequate for the envisaged applications.

\section{REFERENCES}

[1] Werner, D. H. and R. Mittra, Frontiers in Electromagnetics, IEEE Press, New York, 2000.

[2] Vinoy, K. J., Fractal shaped antenna elements for wide and multiband wireless applications, "Thesis, Pennsylvania, Aug. 2002.

[3] Puente, C., J. Romeu, R. Pous, and A. Cardama, On the behavior of the Sierpinskimulti-band fractal antenna," IEEE Transactions on Antennas and Propagation, Vol. 46, 517\{524, 1998.

[4] Puente, C., J. Romeu, R. Pous, and R. Bartoleme, Perturbation of the Sierpinski antenna toallocate operating bands," Electron. Lett., Vol. 32, 2186\{2188, 1996\}.

[5] Puente, C., J. Romeu, and A. Cardama, The Koch monopole a small fractal antenna," IEEETransactions on Antennas and Propagation, Nov. 2000.

[6] Wen-Ling Chen, Guang-Ming Wang and Chen-XinZang, "SmallSize Microstrip Patch Antennas Combining Koch and Sierpinski Fractal Shapes," IEEE Antennas and Wireless Propagation Letters, Vol. 7, pp. 738-741, 2008.

[7] Mahdi Naghshvarian-Jahromi, "Novel Wideband Planar Fractal Monopole Antenna," IEEE Transaction on Antennas and Propagation, Vol. 56, No. 12, pp. 3844-3849, December 2008.

[8] JaonGemio, JosepParron Granados, and JordiSolerCastany, "Dual Band Antenna with Fractal Based Ground Plane for WLAN Application," IEEE Antennas and Wireless Propagation Letters, Vol. 8, pp. 748-751, 2009.

[9] J. Guterman, A. A. Moreira and C. Peixeiro, "Dual-Band Miniaturized Microstrip Fractal Antenna for a Small GSM1800 + UMTS Mobile Handset," IEEE Melecon 2004, Dubrovnik, Croatia, pp. 499-501, May 12-15, 2004.

[10] Hammerstad, E., and Jensen, O. 1980. "Accurate Models for Microstrip Computer Aided Design" IEEE MTT Int. Microwave Symp. Digest, Washington, D. C., 407-409.

[11] Bahl, I. J., and Bhartia, P. 1980. Microstrip Antennas, Dedham, MA, Artech House.

[12] James, J. R., and Hall, P.S. (Eds.) 1989. Handbook of Microstrip Antennas, IEE Electromagnetic Wave Series. 